\title{
Hungry bone syndrome after parathyroidectomy: Incidence and predictive factors
}

\author{
Sameh Mezri ${ }^{*}$, Sameh Sayhi ${ }^{2}$, Hadhemi Ben Chikha ${ }^{1}$, Rania Ben M'hamed ${ }^{1}$ and Khemaies Akkari ${ }^{1}$ \\ ${ }^{1}$ ENT and maxillofacial surgery department. Military hospital of Tunis. Tunisia \\ ${ }^{2}$ Internal department of medicine. Military hospital of Tunis. Tunisia
}

\begin{abstract}
Introduction: The hungry bone syndrome (HBS) is an important complication often under diagnosed that occurs essentially after parathyroidectomy for primary hyperparathyroidism (PHP). Many risk factors had been identified to predict this complication such as old age, size of resected parathyroid glands and preoperative serum parathyroid hormone level.

Observations: We report three cases of hungry bone syndrome developed after parathyroidectomy for hyperparathyroidism. Hypocalcaemia was objectified immediately on postoperative with a generalized tetanus attack in the two patients. One patient has developed cramps and tingling of the limbs. An intravenous calcium infusion at a rate of $6 \mathrm{~g}$ elemental calcium $(\mathrm{Ca}) / \mathrm{Day}$ was started with oral alfacalcidol 2 micrograms daily. An oral calcium supplement was prescribed. The tingling disappeared on postoperative with a normalization of the calcium serum level in the three cases.
\end{abstract}

Conclusion: HBS is a serious complication after parathyroidectomy for hyperparathyroidism. All risk factors should be indentified in PHP patients. A strategy to prevent its occurrence must be done.

\section{Introduction}

The hungry bone syndrome (HBS) is an important complication often under diagnosed that occurs essentially after parathyroidectomy for primary hyperparathyroidism (PHP) or secondary hyperparathyroidism (SHPT). It is defined as a prolonged hypocalcaemia with hypophosphataemia hat exacerbated by suppressed parathyroid hormone (PTH) levels [1,2]. Indeed, intensive bone turnover and excessive greed for calcium is developed during the HBS [3].

Many risk factors had been identified to predict HBS in HPT such as old age, size of resected parathyroid glands, preoperative serum parathyroid hormone $(\mathrm{PTH})$ level, preoperative serum alkaline phosphatase (ALP) level and serum urea nitrogen concentration [2,4$6]$.

Unfortunately, only few publications found that young age, high body weight, high preoperative serum ALP level, and low preoperative serum calcium level predicted the development of HBS [2].

The aim of this study is to alert physician that this serious complication could be seen in both SHPT and HPT even if bone abnormality is quiet different between the two populations.

\section{Observations}

During the period 2013-2018, 35 parathyroidectomy for PHP and 42 for SHPT were performed. Among them, three patients developed an HBS.

\section{Clinical report 1}

A 66-year-old female patient was admitted with complaints of bone pain and exploration of multiple renal lithiasis. Clinical examination found a thyroid goiter without any compression sign.
The biological analysis demonstrated: a preoperative serum calcium level at $2.71 \mathrm{mmol} / \mathrm{l}$. Hypophosphataemia at $0.7 \mathrm{mmol} / \mathrm{l}$, PTH level attended:253 pg/ml, vitamin D deficiency level: $20 \mathrm{ug} / 1$ (Normal level $>50 \mathrm{ug} / \mathrm{l}$ ) and thyroid stimulating hormone (TSH) was normal.

Her neck ultrasound showed a multinodular goiter at the expense of two lobes, the MIBI scintigraphy revealed hyperfixation of the right inferior parathyroid. Bone densitometry recorded indicated a bone demineralization. She was referred to otolaryngologist for neck exploration.

Preoperatively, the left superior parathyroid was large with a goiter. The patient had superior left parathyroidectomy associated to thyroidectomy. The anatomopathologist confirmed the presence of an adenoma in both parathyroid and thyroid.

Hypocalcaemia was objectified immediately on postoperative when she developed a generalized tetanus attack. An intravenous calcium infusion at a rate of $6 \mathrm{~g}$ elemental calcium (Ca)/Day was started during three days with oral alfacalcidol 2 micrograms daily. An oral calcium supplement was prescribed $4 \mathrm{~g}$ /day from the third day. The tingling disappeared on postoperative with a normalization of the calcium serum level (Figure1), the PTH serum level (22 UI/l) and the vitamin D serum level (55 ug/l) after supplements: $1,5 \mathrm{~g}$ daily of oral calcium associated to alphacalcidol 1 micrograms per day.

*Correspondence to: Sameh Mezri, ENT and maxillofacial surgery department. Military hospital of Tunis. Tunisia, Tel: +0021697170323; E-mail: sameh_sayhi@yahoo.fr

Key words: hungry bone syndrome, parathyroidectomy

Received: May 11, 2019; Accepted: June 20, 2019; Published: June 24, 2019 


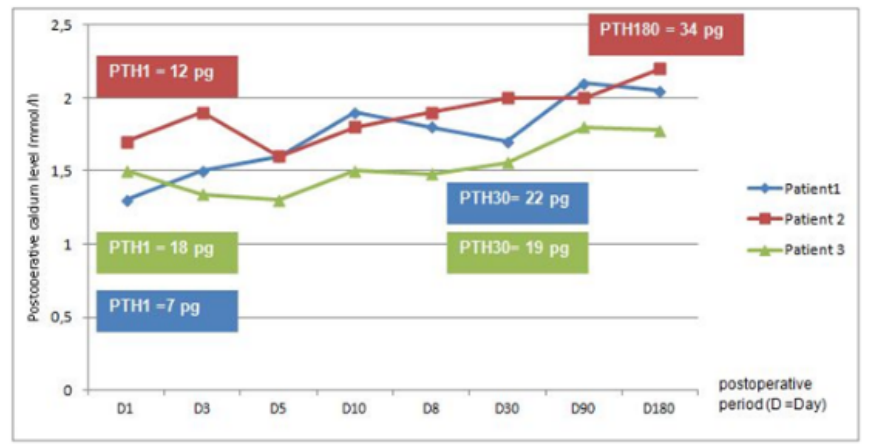

Figure 1. Evolution of calcium level of the three patients

Actually she had 4 years of follow up and she had a definitive HBS.

\section{Clinical report 2}

A 46-year-old male patient with a medical history of pathological fracture of the lower limb. He was complaining about bone pain. Clinical examination didn't found any anomaly.

The biological analysis showed: a preoperative serum calcium level at $2.35 \mathrm{mmol} / \mathrm{l}$, serum phosphataemia level at $1.29 \mathrm{mmol} / \mathrm{l}$, PTH level Attended: 658pg/ml (nine times the normal level) and thyroid stimulating hormone (TSH) was normal.

Both neck ultrasound and MIBI scintigraphy had demonstrated an abnormal right inferior parathyroid.

The neck exploration found a huge right inferior parathyroid that was addressed to the anatomopathological examination. The presence of adenoma in parathyroid was confirmed.

The patient has developed a generalized tetanus attack with severe Hypocalcaemia immediately on postoperative. An intravenous calcium infusion at a rate of $6 \mathrm{~g}$ elemental calcium (Ca)/Day was started during three days with oral alfacalcidol 2 micrograms daily. An oral calcium supplement was prescribed $3 \mathrm{~g} /$ day from the fourth day with oral alfacalcidol 1 micrograms daily.

A normalization of the calcium serum level $(2.2 \mathrm{mmol} / \mathrm{l})$ and PTH serum level (34 UI/l) was obtained 15 months postoperative (Figure1). On any tentative of supplements degression tingling appears associated to hypocalcaemia.

\section{Clinical report 3}

A 39-year-old male patient with a medical history of chronic kidney disease and dialysis since nineteen years old. Clinical examination of the neck was normal.

The biological analysis showed: a preoperative serum calcium level at $2.3 \mathrm{mmol} / \mathrm{l}$, PTH level attended: $2841 \mathrm{pg} / \mathrm{ml}$, vitamin D deficiency level: $7 \mathrm{ug} / \mathrm{l}$ (Normal level $>50 \mathrm{ug} / \mathrm{l}$ ) and thyroid stimulating hormone (TSH) was normal.

The patient had a subtotal parathyroidectomy (7/8). The presence of hyperplasia in the 3.5 parathyroid's glands was confirmed.

The patient has developed cramps and tingling of the limbs immediately on postoperative. The serum calcium level attended 1.5 $\mathrm{mmol} / \mathrm{l}$, PTH level on the blood was $18 \mathrm{pg} / \mathrm{ml}$ and the electrocardiogram did not show any sign of hypocalcaemia. The serum phosphataemia level was collapsed.
An intravenous calcium infusion at a rate of $6 \mathrm{~g}$ elemental calcium (Ca)/Day was started during three days with oral alfacalcidol 2 micrograms daily. An oral calcium supplement was prescribed 3g/day from the fourth day with oral alfacalcidol 1 micrograms daily.

The serum calcium level dropped progressively after operation until 3 weeks later when serum calcium reached $1,56 \mathrm{mmol} / \mathrm{l}$ and increased then attending $1.8 \mathrm{mmol} / \mathrm{l}$ (Figure1).

Length of hospital stay was 35 days after operation.

An oral calcium supplement was prescribed 4g/day with alphacalcidol 2 micrograms per day.

\section{Discussion}

These 3 cases reports showed the severity and potentially dangerous complications of postoperative hypocalcaemia after primary or secondary parathyroïdectomy.

The most incriminated mechanism is a transienthypoparathyroidism due to a slow recovering function of the rest of parathyroid which was inhibiting by de hyperfunctional adenoma [6].

The normality of the PTH level for the three patients after surgery and the important decrease of serum phosphate and calcium level shows that it is not the only mechanism but it is associated with a HBS.

This under diagnosed syndrome may appear in different situations of intense bone remodeling such as PHP and SHPT, increasing the avidity of bone to calcium. That's why we find an important and extended hypocalcaemia.

Clinical signs can vary from acroparesthesias and cramps to tetany, seizures or confusion. Two of our patients had developed a tetanus attack immediately in postoperative care.

Cardiac symptoms found are QT prolongation and arrhythmias $[7,8]$. no one of our patient had cardiac repercussion.

Post-surgery, hypocalcaemia is expected and is usually resolved within 2-4-days. If it persists for more than 4 days or drops below 2.1 $\mathrm{mmol} / \mathrm{L}, \mathrm{HBS}$ is diagnosed [7].

The biological analysis shows usually hypophosphatemia associated to severe hypocalcaemia.

Even if literature related to HBS is limited, some prognostic factors had been identified for development of potential HBS based on the observations of small series of patient populations [9].

Ho and cols highlighted that young age and high body weight were risk factors of HBS after total parathyroidectomy in 62 dialysis patients with secondary hyperparathyroidism [2].

Our patient had 39-year-old and had a severe HBS with a long period of hospitalization.

Nasiri and cols who studied 80 patients who underwent surgery for PHP, found a correlation between preoperative calcium, PTH and ALP, and the decrease in postoperative calcium levels [10]. Ho and cols also demonstrated that these three factors independently predicted the development of HBS [2].

Yang and cols found that a lower preoperative serum calcium level and higher preoperative serum ALP level were independent predictors for HBS in a study that included 252 hemodialysis patients undergoing successful total parathyroidectomy with autotransplantation [11]. 
Kald and Mollerup have established that preoperative serum parathyroid hormone level higher than $25 \mathrm{pmol} / \mathrm{l}$ is risk factor for severe postoperative hypocalcaemia after surgery for primary hyperparathyroidism [12]. All our patients had a high serum PTH level.

The ALP serum level was not provided for none of our patients. This biomarker can reflect the bone formation and the calcium requirement.

Kald and Mollerup have established that concomitant parathyroidectomy and thyroid surgery, or history of neck-area surgery are risk factors for severe postoperative hypocalcaemia after surgery for primary hyperparathyroidism [12].

The 66-year-old female patient had both thyroidectomy and parathyroidectomy but also bone demineralization in densitometry. The 46-year-old male patient with a medical history of pathological fracture had also bone form that can contribute to the occurrence of HBS.

In hyperparathyroidism PTH stimulates the conversion of 25hydroxy-vitamin $\mathrm{D}$ into its active metabolite. Thus vit $\mathrm{D}$, which plays a role in the metabolism of calcium, is reduced [2]. Vitamin D increases the risk of postoperative hypocalcaemia and development of HBS. A vitamin D deficiency was observed in a case of PHP and SHPT in our patients.

The target of HBS treatment is to correct hypocalcaemia using the intravenous way then the oral way. The treatment can be prolonged until normalization of the biological level and bone signs. All our patients had definitive HBS and still take drugs until now.

Prevention is not yet codified but some authors consent that paricalcitol decrease preoperative ALP and the frequency of HBS $[13,14]$. Others did not find any significant difference of risk between patients with or without HBS receiving active vitamin D sterols such as paricalcitriol or cinacalcet preoperatively [2].

\section{Conclusion}

HBS is a serious complication that occurs essentially after parathyroidectomy for hyperparathyroidism. All risk factors should be indentified in PHP or SHPT patients. A strategy to prevent its occurrence must be done. A need of prospective multicenter study will certainly contribute to establish an adequate care.

\section{Conflicts of interest}

All authors declare no conflict of interest.

\section{References}

1. Albright F, Reifenstein EC (1950) The Parathyriod Glands and Metabolic Bone Disease. Ulster Med J 19: 130-131. [Crossref]

2. Ho LY, Wong PN, Sin HK, Wong YY, Lo KC, et al. (2017) Risk factors and clinical course of hungry bone syndrome after total parathyroidectomy in dialysis patients with secondary hyperparathyroidism. BMC Nephrol 18: 12. [Crossref]

3. Boeckler P, Grunenberger F, Ruellan A, Vignon F, Weber JC, et al. (2002) Hungry bone syndrome after surgical treatment of severe primary hyperparathyroidism: about 3 cases. Ann Endocrinol 63: 8-12. [Crossref]

4. Brasier AR, Nussbaum SR (1988) Hungry bone syndrome: clinical and biochemical predictors of its occurrence after parathyroid surgery. Am JMed 84: 654-660. [Crossref]

5. Mittendorf EA, Merlino JI, McHenry CR (2004) Post-parathyroidectomy hypocalcemia incidence, risk factors, and management. Am Surg 70: 114-119. [Crossref]

6. Kaya C, Tam AA, Dirikoç A, Kılıçazgan A, Kılıc M, et al. (2016) Hypocalcemia development in patients operated for primary hyperparathyroidism: Can it be predicted preoperatively? Arch Endocrinol Metab 60: 465-471. [Crossref]

7. Anwar F, Abraham J, Nakshabandi A, Lee E (2018) Treatment of hypocalcemia in hungry bone syndrome: A case report. Int J Surg Case Rep 51: 335-339. [Crossref]

8. Chou FF, Chen JB, Lee CH, Chen SH, Sheen-Chen SM (2001) Parathyroidectomy Can Improve Bone Mineral Density in Patients With Symptomatic Secondary Hyperparathyroidism. Arch Surg 136: 1064-1068. [Crossref]

9. Smith D, Murray BF, McDermott E, O'Shea D, McKenna MJ, et al. (2005) Hungry bones without hypocalcaemia following parathyroidectomy. J Bone Miner Metab 23: 514-515. [Crossref]

10. Nasiri S, Sorush A, Mehrkhani F, Hedayat A (2007) Could we predict adenoma weigh and postoperative serum calcium level with preoperative serum biochemical markers in patients with primary hyperparathyroidism. $J$ Surg 16: 1 .

11. Yang G, Zha X, Mao H, Yu X, Wang N, et al. (2018) Hypocalcemia-based prediction of hungry bone syndrome after parathyroidectomy in hemodialysis patients with refractory secondary hyperparathyroidism. J Int Med Res 46: 4985-4994. [Crossref]

12. Kald BA, Mollerup CL (2002) Risk factors for severe postoperative hypocalcaemia after operations for primary hyperparathyroidism. Eur J Surg Acta Chir 168: 552-556. [Crossref]

13. Cozzolino M, Ketteler M, Martin KJ, Sharma A, Goldsmith D, et al. (2014) Paricalcitolor cinacalcet-centred therapy affects markers of bone mineral disease in patients with secondary hyperparathyroidism receiving haemodialysis: results of the IMPACT-SHPT study. Nephrol Dial Transplant 29: 899-905. [Crossref]

14. Crea N, Pata G, Casella C, Capelli C, Salemi B (2012) Predictive factors for postoperative severe hypocalcemia after parathyroidectomy for primary hyperparathyroidism. $A m$ Surg 78: 352-358. [Crossref]

Copyright: (C2019 Mezri S. This is an open-access article distributed under the terms of the Creative Commons Attribution License, which permits unrestricted use, distribution, and reproduction in any medium, provided the original author and source are credited. 